\title{
Managing hyperthyroidism in pregnancy: current perspectives
}

\author{
This article was published in the following Dove Press journal: \\ International Journal of Women's Health \\ 19 September 2016 \\ Number of times this article has been viewed
}

\author{
Stine Linding Andersen ${ }^{1,2}$ \\ Peter Laurberg ${ }^{1,3, \dagger}$ \\ 'Department of Endocrinology, \\ Aalborg University Hospital, \\ ${ }^{2}$ Department of Clinical Biochemistry, \\ Aalborg University Hospital, \\ ${ }^{3}$ Department of Clinical Medicine, \\ Aalborg University, Aalborg, Denmark \\ †Peter Laurberg passed away on \\ June 20,2016
}

Correspondence: Stine Linding Andersen Department of Endocrinology, Aalborg University Hospital, Søndre Skovvej 15, Aalborg 9000, Denmark Tel +4597663685 Email stine.a@rn.dk

\begin{abstract}
Hyperthyroidism in women who are of childbearing age is predominantly of autoimmune origin and caused by Graves' disease. The physiological changes in the maternal immune system during a pregnancy may influence the development of this and other autoimmune diseases. Furthermore, pregnancy-associated physiological changes influence the synthesis and metabolism of thyroid hormones and challenge the interpretation of thyroid function tests in pregnancy. Thyroid hormones are crucial regulators of early development and play an important role in the maintenance of a normal pregnancy and in the development of the fetus, particularly the fetal brain. Untreated or inadequately treated hyperthyroidism is associated with pregnancy complications and may even program the fetus to long-term development of disease. Thus, hyperthyroidism in pregnant women should be carefully managed and controlled, and proper management involves different medical specialties. The treatment of choice in pregnancy is antithyroid drugs (ATDs). These drugs are effective in the control of maternal hyperthyroidism, but they all cross the placenta, and so need careful management and control during the second half of pregnancy considering the risk of fetal hyper- or hypothyroidism. An important aspect in the early pregnancy is that the predominant side effect to the use of ATDs in weeks 6-10 of pregnancy is birth defects that may develop after exposure to available types of ATDs and may be severe. This review focuses on four current perspectives in the management of overt hyperthyroidism in pregnancy, including the etiology and incidence of the disease, how the diagnosis is made, the consequences of untreated or inadequately treated disease, and finally how to treat overt hyperthyroidism in pregnancy.
\end{abstract}

Keywords: thyroid, hyperthyroidism, Graves' disease, pregnancy, antithyroid drug, fetal programming

\section{Introduction}

Hyperthyroidism is defined by abnormally high levels of thyroid hormone caused by an increased synthesis and secretion of thyroid hormone from the thyroid gland. ${ }^{1}$ The term "thyrotoxicosis", on the other hand, is used to describe "excess of thyroid hormone", and this can be due to an increased synthesis of thyroid hormone in the thyroid gland (hyperthyroidism), but may also occur in the absence of hyperthyroidism, eg, in patients with leakage of thyroid hormone from the thyroid gland (thyroiditis) or in patients with excess intake of thyroid hormone. ${ }^{1}$

Careful management and control of patients suffering from hyperthyroidism are important to prevent the possible complications related to the disease itself or to the treatment. ${ }^{1-3}$ A special situation is hyperthyroidism in women of reproductive age who are or may in the future become pregnant. ${ }^{4,5}$ Hyperthyroidism in pregnancy is a special clinical situation because physiological changes related to the pregnant state challenge the interpretation of thyroid function test and because potential complications related to 
the disease and/or the treatment may compromise the health of the pregnant woman and also the developing fetus. ${ }^{4,5}$

Hyperthyroidism can be overt (suppressed thyroidstimulating hormone [TSH] and elevated T3 [triiodothyronine] and/or T4 [tetraiodothyronine] in a blood sample) or subclinical (suppressed TSH and normal T3 and T4). ${ }^{2,3}$ This review focuses on the management of overt hyperthyroidism in pregnant women and discusses the following current perspectives: 1) the etiology and incidence of overt hyperthyroidism in pregnancy, 2) the diagnosis of overt hyperthyroidism in pregnancy, 3) the consequences of untreated overt hyperthyroidism in pregnancy, and 4) the treatment of overt hyperthyroidism in pregnancy.

\section{Etiology and incidence of hyperthyroidism in pregnancy Etiology of hyperthyroidism}

Overt hyperthyroidism can be divided into different subtypes from the underlying etiology, and the three most common subtypes are Graves' disease, multinodular toxic goiter, and solitary toxic adenoma. ${ }^{6}$ All types show a female predominance (most pronounced for Graves' disease and multinodular toxic goiter), but there is a notable difference in the typical age at onset of these various types of hyperthyroidism (Figure 1). ${ }^{6}$ In a Danish population-based

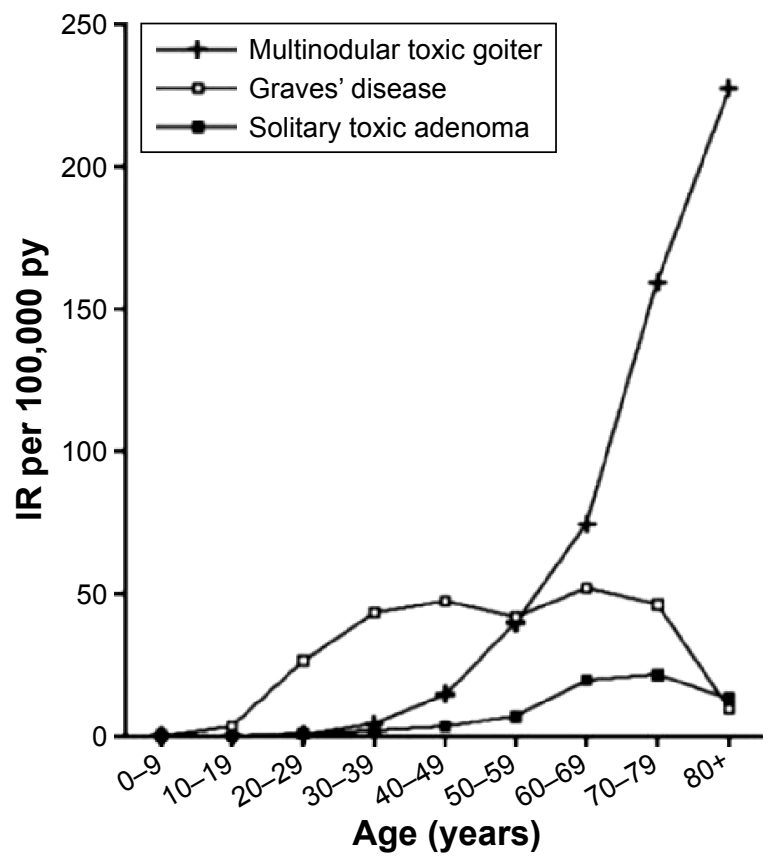

Figure I Age-specific IR per 100,000 py for the most common types of hyperthyroidism in Denmark (Graves' disease, multinodular toxic goiter, and solitary toxic adenoma).

Note: Reproduced with permission from Carlé A, Pedersen IB, Knudsen N, et al. Epidemiology of subtypes of hyperthyroidism in Denmark: a population-based study. Eur J Endocrinol. 201 I;164(5):80I-809.6

Abbreviations: IR, incidence rate; py, person-years. study with individual review and subclassification of 1,682 new cases of overt hyperthyroidism, Graves' disease was the predominant type of hyperthyroidism in young individuals, and the incidence of this subtype was stable with increasing age (Figure 1). ${ }^{6}$ On the other hand, multinodular toxic goiter and solitary toxic adenoma were rare in young individuals, and the incidence was increasing with age, particularly for multinodular toxic goiter, which is the predominant type of hyperthyroidism in older individuals in Denmark (Figure 1). ${ }^{6}$

Graves' disease is an autoimmune disease in which hyperthyroidism is caused by the production of autoantibodies that are directed against the TSH receptor and stimulate the thyroid gland to an increased production of thyroid hormone. ${ }^{1}$ Biochemically, increased serum levels of TSH receptor antibodies (TRAb) are detectable in 95\% of patients with Graves' disease. ${ }^{7}$ Hyperthyroidism caused by multinodular toxic goiter or toxic solitary adenoma is not considered of autoimmune origin, but develops from thyroid autonomy, where the synthesis of thyroid hormone occurs independently of regulation by TSH. ${ }^{8}$ Such thyroid autonomy is often seen as a late consequence of iodine deficiency. ${ }^{8}$

\section{Incidence of hyperthyroidism in pregnancy}

Graves' disease is the predominant type of overt hyperthyroidism in women of reproductive age and thereby also the main type of overt hyperthyroidism in pregnancy. ${ }^{6}$ However, other types of thyrotoxicosis may occur in early pregnancy, and they should be distinguished from the hyperthyroidism of Graves' disease. ${ }^{4,5}$

Physiological changes in the pregnant state affect the function of the thyroid gland. The steep increase in human chorionic gonadotropin (hCG) from early pregnancy stimulates the thyroid gland to an increased production of thyroid hormone. hCG is a glycoprotein synthesized in and released from the placenta, and it stimulates the TSH receptor due to structural similarities with TSH. ${ }^{9}$ Gestational hyperthyroidism is a nonautoimmune transient disorder that occurs in the first trimester of pregnancy and is caused by the peak in hCG levels during early pregnancy. ${ }^{4,5}$ Gestational hyperthyroidism is often associated with hyperemesis gravidarum, and clinically it may be difficult to distinguish from Graves' hyperthyroidism. The presence of TRAb strongly supports a diagnosis of Graves' disease..$^{2-4}$

The incidence of Graves' disease varies in and around pregnancy. ${ }^{10}$ Pregnancy is associated with profound changes in the maternal immune system, with a general immune 


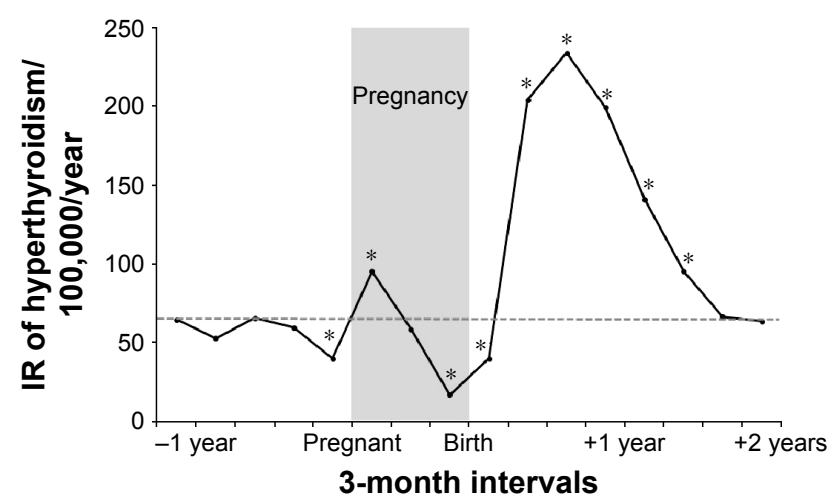

Figure 2 IR of maternal hyperthyroidism in 3-month intervals before, during, and after the first pregnancy leading to birth of a live-born child from 1999 to 2008 in a Danish population-based study of 403,958 women.

Notes: The dashed horizontal line indicates the overall IR of maternal hyperthyroidism in women aged I5-45 years in the study period from 1997 to 2010 *Indicates significant difference from the overall IR. Republished with permission of the Endocrine Society, from Andersen SL, Olsen J, Carlé A, Laurberg P. Hyperthyroidism incidence fluctuates widely in and around pregnancy and is at variance with some other autoimmune diseases: a Danish population-based study. J Clin Endocrinol Metab. 2015;100(3):1164-1171;:10 permission conveyed through Copyright Clearance Center, Inc.

Abbreviation: IR, incidence rate.

suppression during the pregnancy followed by an immune rebound after the birth of the child. ${ }^{11}$ Such alterations may influence the onset of autoimmune diseases (Figure 2). ${ }^{10}$ In a Danish population-based study of 403,958 women, the incidence of nontransient hyperthyroidism (considered to be Graves' disease) was high in early pregnancy, which was followed by a gradual decline during the pregnancy and then a considerable increase in incidence postpartum (Figure 2). ${ }^{10}$ The women identified with hyperthyroidism in early pregnancy did not suffer from transient hyperthyroidism, ${ }^{10}$ but it can be speculated that the hCGmedicated increase in thyroid hormone production in early pregnancy may trigger the development of Graves' disease in susceptible individuals. ${ }^{12}$ Likewise, Graves' disease that developed prior to a pregnancy may aggravate in early pregnancy. ${ }^{13}$

\section{Diagnosis of hyperthyroidism in pregnancy \\ Changes in thyroid hormone metabolism}

The diagnosis of overt hyperthyroidism is based on the measurement of a suppressed TSH and an elevated T3 and/or T4. ${ }^{1-3}$ The physiological changes during a pregnancy may, however, challenge the interpretation of thyroid function test results. ${ }^{9}$ One physiological mechanism is the increase of hCG in early pregnancy that stimulates the thyroid gland to increase production of thyroid hormone and tends to decrease TSH. ${ }^{9}$ Another physiological mechanism is the increased activity of the type-3-deiodinase enzyme in the placenta that inactivates T3 and T4 and tends to increase TSH. ${ }^{9}$ Finally, the pregnancy-associated high levels of estrogen increase thyroxine-binding globulin with a concomitant increase in total T3 and total T4. ${ }^{9}$

One consideration related to these physiological changes is how to evaluate the peripheral thyroid hormone concentrations in pregnant women. The change in thyroxine-binding globulin concentrations, and thereby in the concentration of total thyroid hormone, has led to the use of free thyroid hormone assays in many countries. Direct measurement of free thyroid hormone concentrations includes an initial separation of free and protein-bound thyroid hormone by ultrafiltration or equilibrium dialysis. However, in routine laboratories, free thyroid hormones are usually determined using automatic immunoassays, and all these provide an indirect measurement of free thyroid hormone concentrations with no initial separation. Thus, free thyroid hormone concentrations change in relation to the physiological changes during a pregnancy. ${ }^{14}$ Furthermore, the methods used to determine the free thyroid hormone concentrations in different immunoassays are not identical, and this diversity stresses the importance of laboratory-specific reference ranges. ${ }^{15}$

Another consideration is the changes in thyroid function test results during a pregnancy. It has often been recommended to use trimester-specific reference ranges in pregnant women. ${ }^{2-4}$ However, the physiological changes in the first trimester of pregnancy are so rapid that such a definition may be too simple. ${ }^{16}$ Figure 3 depicts the lower reference limit for TSH and upper reference limit for free T4 (fT4) during early pregnancy determined using the Dimension Vista (Siemens Healthcare Diagnostics GmbH, Eschborn, Germany) immunoassay in healthy Danish pregnant women stratified by week of pregnancy. ${ }^{16}$ The dashed horizontal lines indicate the reference limits for nonpregnant adults provided by the manufacturer. The diagnosis of overt hyperthyroidism in nonpregnant adults would be defined by TSH below this lower reference limit of $0.358 \mathrm{mU} / \mathrm{L}$ and fT 4 above the upper reference limit of $18.8 \mathrm{pmol} / \mathrm{L}$. As can be seen from Figure 3, these reference limits would not correctly classify pregnant women with overt hyperthyroidism. ${ }^{16}$ For TSH, the lower reference limit was higher in early pregnancy and lower in weeks 9-12 of pregnancy. For fT4, the difference between the upper reference limit in nonpregnant and pregnant women was less pronounced, however, with a tendency toward higher levels in gestational weeks 9-12 and lower levels from week 13 and onward. Thus, in the diagnosis of hyperthyroidism in pregnant women, week-to-week-specific reference ranges in early pregnancy would be preferable. ${ }^{16}$ 

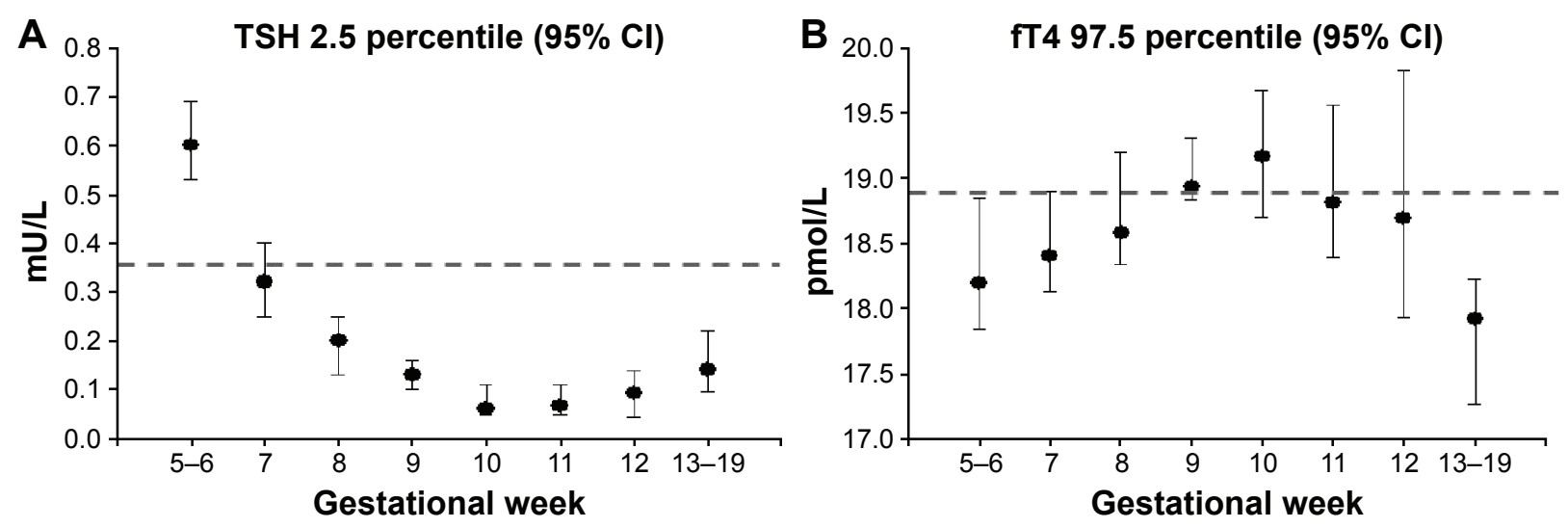

Figure 3 Reference limits for the diagnosis of hyperthyroidism in early pregnancy established with the Dimension Vista (Siemens) automatic immunoassay.

Notes: (A) and (B) illustrate the 2.5 percentile for TSH and the 97.5 percentile for $\mathrm{fT} 4$ with $(95 \% \mathrm{Cl})$, respectively. Dashed horizontal lines indicate the reference limit in nonpregnant adults as reported by the manufacturer. Republished with permission of the Endocrine Society, from Laurberg P, Andersen SL, Hindersson P, Nohr EA, Olsen J. Dynamics and predictors of serum TSH and fT4 reference limits in early pregnancy: a study within the Danish National Birth Cohort. J Clin Endocrinol Metab. 2016;10I(6):2484-2492;16 permission conveyed through Copyright Clearance Center, Inc.

Abbreviations: TSH, thyroid-stimulating hormone; Cl, confidence interval; fT4, free T4.

\section{Untreated hyperthyroidism in pregnancy}

\section{Fetal programming?}

Correct diagnosis of hyperthyroidism in pregnant women is important to prevent adverse outcomes of pregnancy. Overt hyperthyroidism is considered as a clinical high-risk situation, and the disease should be carefully diagnosed, managed, and controlled. ${ }^{2-4}$ On the other hand, subclinical hyperthyroidism (suppressed TSH) has not been associated with pregnancy complications. ${ }^{17}$

Thyroid hormones are important developmental factors. ${ }^{18}$ Thyroid hormone receptors are present in the maternal-fetal unit, ${ }^{19}$ and normal levels of thyroid hormone are important in the maintenance of a normal pregnancy. ${ }^{20}$ Both the lack of thyroid hormone and thyroid hormone excess may interfere with the maternal-fetal unit, and women suffering from hyperthyroidism have an increased risk of both early and late pregnancy loss. ${ }^{21}$ Maternal hyperthyroidism is also associated with an increased risk of preterm delivery and low birth weight of the child and may seriously complicate the health of the pregnant women, eg, maternal heart failure and in rare cases even thyroid storm. ${ }^{5}$

Thyroid hormone receptors are also present in the fetal brain, ${ }^{22}$ and levels of maternal thyroid hormones play a crucial role in fetal brain development. ${ }^{23}$ The fetal thyroid gland is increasingly able to synthesize thyroid hormones in the second half of pregnancy, but maternal thyroid hormones are important for fetal development throughout pregnancy. ${ }^{24}$ Evidence from experimental studies have shown that high levels of maternal thyroid hormones may interrupt fetal brain development, ${ }^{25,26}$ and population-based

epidemiological studies have shown an association between maternal hyperthyroidism and the later development of brain-related disease in the child. ${ }^{27}$ In a Danish nationwide study, children born to mothers with hyperthyroidism had an increased risk of developing seizure disorder ${ }^{28}$ and attentiondeficit hyperactivity disorder later in life, ${ }^{29}$ particularly when the mother was first diagnosed with hyperthyroidism after the pregnancy and potentially had undetected high levels of thyroid hormones during the pregnancy. A proposed mechanism is that maternal thyroid disease may program the fetus to later development of disease via subtle structural and/or functional changes during fetal brain development. ${ }^{27}$ Further studies, including studies with actual measurement of maternal thyroid function in pregnancy, are needed to explore this hypothesis.

\section{Treatment of hyperthyroidism in pregnancy Early pregnancy}

Overt hyperthyroidism should be adequately treated to prevent maternal and fetal complications. A matter of clinical attention in early pregnancy is, however, that transient biochemical hyperthyroidism caused by the physiological hCG peak in early pregnancy should not be treated with antithyroid drugs (ATDs). ${ }^{2-4}$ There is no evidence that ATD treatment of this transient physiological hyperthyroidism improves the outcome of pregnancy. ${ }^{2-4}$ A physical examination and repeated thyroid function testing every 2-3 weeks are recommended, and in case of hyperemesis gravidarum, this should be managed with supportive therapy and management of dehydration. 
The treatment of choice for overt hyperthyroidism in pregnant women is ATD. ${ }^{5}$ Radioiodine treatment should not be used in pregnancy. If ATDs are not tolerated, the alternative treatment is thyroidectomy, preferably in the second trimester of pregnancy. ${ }^{2-4}$

ATDs are thioamides that block the synthesis of thyroid hormone in the thyroid gland. ${ }^{30}$ The available drugs include methimazole (MMI) and its prodrug carbimazole (CMZ) as well as propylthiouracil (PTU). The drugs are equally effective in the treatment of hyperthyroidism, and they all pass the placenta, which may lead to fetal hypothyroidism in late pregnancy (see "Late pregnancy" section). ${ }^{31-33}$ The major concern to the use of these drugs in early pregnancy is, however, the potential risk of birth defects. ${ }^{34}$

An association between the use of ATD in early pregnancy and birth defects was first reported in $1972 .{ }^{35}$ In a short publication, it was described that two of eleven mothers who had given birth to a child with a scalp defect had been treated with MMI during pregnancy ${ }^{35}$ Following this, additional cases of birth defects after the use of MMI or CMZ were reported. Many of these birth defects were within a certain group of malformations, which led to the description of a specific MMI embryopathy that included special facial features, aplasia cutis, upper airway atresia, esophageal and other gastrointestinal atresias, abdominal wall defects, and also ventricular septal defects. ${ }^{36-39}$ In recent years, the risk of birth defects evident from case reports has been corroborated in large clinic- and population-based studies. Studies from Japan ${ }^{40}$ and Denmark ${ }^{41}$ both reported an increased risk of birth defects in children exposed to MMI/CMZ. The birth defects involved various organ systems, which are illustrated in the upper part of Figure 4, and includes data from the Danish study. ${ }^{41}$ Furthermore, both studies ${ }^{40,41}$ reported birth defects in line with the previously described MMI embryopathy.

Notably, the Danish study ${ }^{41}$ also found an increased risk of birth defects in children exposed to PTU (lower part of Figure 4). However, the types of birth defects after PTU exposure were different from those observed after MMI/CMZ (Figure 4) and less severe. ${ }^{42}$ PTU-associated birth defects were confined to the face and neck region (preauricular sinus, fistula, and cysts) and the urinary tract (Figure 4). Although less severe, the majority of cases had been surgically treated. ${ }^{42}$

Current international guidelines recommend the use of PTU in the first trimester of pregnancy considering the risk of birth defects after $\mathrm{MMI} / \mathrm{CMZ}$ and to consider shifting from PTU to MMI/CMZ after the first trimester considering

\section{MMI/CMZ exposure}

Musculoskeletal, others DQ79

Integumentary DQ80-84

Digestive DQ39-45

Eye DQ10-15

Urinary DQ60-64

Respiratory DQ30-38

Circulatory DQ20-28

Face and neck, others DQ18

PTU exposure

Face and neck, others DQ18

Urinary DQ60-64

Respiratory DQ30-38

Circulatory DQ20-28

Digestive DQ39-45

Integumentary DQ80-84

Eye DQ10-15

Musculoskeletal, others DQ79

No ATD (reference)

$0.02 \quad 0.04$

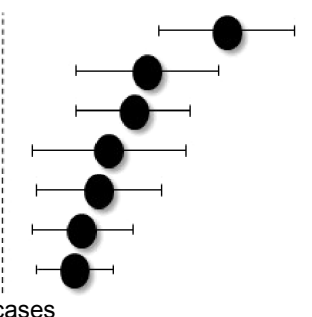

No cases

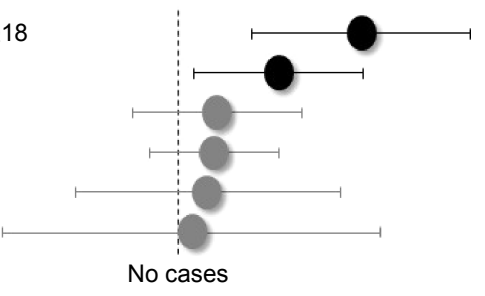

No cases

$\longrightarrow$

Figure 4 Adjusted OR with $95 \% \mathrm{Cl}$ for subtypes of birth defects in I,097 children exposed to MMI/CMZ and 564 children exposed to PTU in early pregnancy versus the reference group of 811,730 children not exposed to ATD.

Notes: Musculoskeletal defects were various types of abdominal wall defects, integumentary defects included aplasia cutis and face and neck defects included preauricular sinus and cysts. Associations marked with gray circles were not statistically significant. Republished with permission of the Endocrine Society, from Andersen SL, Olsen J, Wu CS, Laurberg P. Birth defects after early pregnancy use of antithyroid drugs: a Danish nationwide study. J Clin Endocrinol Metab. 2013;98(I I):4373-438I; permission conveyed through Copyright Clearance Center, Inc.

Abbreviations: $\mathrm{OR}$, odds ratio; $\mathrm{Cl}$, confidence interval; $\mathrm{MMI}$, methimazole; CMZ, carbimazole; PTU, propylthiouracil; ATD, antithyroid drug.

the risk of liver failure associated with the use of PTU..$^{2-4}$ Liver failure during treatment with PTU has been a matter of concern because PTU was the third most common drug-related cause of liver transplantation in the USA..$^{43,44}$ However, in a recent Danish population-based study, the frequency of severe side effects to the use of ATDs in the general population and in pregnancy specifically was compared. Both agranulocytosis and liver failure were very rare events in pregnancy, with birth defects being the predominant side effect. ${ }^{34}$

Further studies within this field are needed, including more studies on alternative treatments to the use of ATD in pregnancy. Table 1 summarizes the current proposals on the treatment of overt hyperthyroidism in early pregnancy. Notably, the critical window of ATD exposure and the risk of birth defects are from weeks 6 to 10 of pregnancy. ${ }^{45}$ An important aspect in the proposals is to discuss future pregnancy with a woman who may become pregnant, including the strategy to detect a pregnancy as early as possible. For the responsible physician, it is important to consider the clinical indication of continued ATD 
Table I Proposals on the treatment of hyperthyroidism in women who are or plan to become pregnant

Planned pregnancy

- Women who receive ATD treatment should contact the responsible physician if they are planning a pregnancy.

- When pregnancy is planned, treatment can be shifted to PTU before pregnancy, particularly in younger women with regular menses in whom rapid conception is likely.

- The conversion factor from MMI to PTU is I:20, eg, $200 \mathrm{mg}$ PTU per day replaces $10 \mathrm{mg}$ MMI (or I5 mg CMZ).

Detected pregnancy

- Women who receive ATD treatment should be instructed to detect pregnancy as early as possible.

- Women who receive ATD treatment should perform a pregnancy test on the first days of a missing menstrual period, if pregnancy is a possibility.

- When pregnancy is detected, the woman should contact the responsible physician immediately to evaluate whether current ATD treatment should be continued, changed, or stopped.

- The responsible physician should evaluate the need for ATD treatment.

- If ATD treatment is considered necessary in the first trimester of pregnancy, PTU should be used.

- If ATD treatment is not considered necessary, weekly testing of thyroid function should be performed throughout the first trimester of pregnancy.

- If treatment is considered necessary after the first trimester of pregnancy, MMI/CMZ or PTU can be used.

Abbreviations: MMI, methimazole; CMZ, carbimazole; PTU, propylthiouracil; ATD, antithyroid drug.

treatment when a pregnancy is detected. Such evaluation should be based on thyroid function test results, levels of TRAb, current dose and duration of ATD treatment, and clinical symptoms. ${ }^{9}$

\section{Late pregnancy}

An important aspect in the management of maternal hyperthyroidism in late pregnancy is the thyroid function of the fetus. ${ }^{46}$ TRAb, which are the cause of Graves' hyperthyroidism in the mother, cross the placenta, and the concentration of TRAb is similar in maternal and fetal blood in late pregnancy. ${ }^{47}$ Thus, TRAb can also stimulate the fetal thyroid gland to produce excess thyroid hormones. In the second half of pregnancy, when the fetal thyroid gland is capable of synthesizing thyroid hormones, fetal hyperthyroidism can occur. As already mentioned, all available ATDs pass the placenta, and when used for the treatment of maternal hyperthyroidism, these drugs will also treat the fetal hyperthyroidism. However, there is a risk of fetal hypothyroidism during such treatment. ${ }^{48,49}$ Thyroid autoimmunity tends to attenuate during the pregnancy ${ }^{50}$ in line with the general suppression of the immune system ${ }^{11}$ and the gradual decline in the incidence of maternal hyperthyroidism in late pregnancy (Figure 2).$^{10}$ Following this, the dose of ATD needed to keep the mother euthyroid may change during the pregnancy, and it is important to reduce the dose if indicated, because both MMI/CMZ and PTU tend to overtreat the fetus with a risk of fetal hypothyroidism, when the mother is euthyroid. ${ }^{33}$

In nonpregnant patients with Graves' hyperthyroidism, a treatment regimen called "block replacement therapy" may be used..$^{2-4}$ This treatment is based on a combination of ATD and thyroid hormone, which makes it possible to overtreat the hyperthyroidism and to keep the patient euthyroid with thyroid hormone replacement. Block replacement therapy should not be used in pregnant women because the high dose of ATD will overtreat the fetus and the thyroid hormone replacement therapy will only have minimal effect in the fetus with a risk of severe fetal hypothyroidism. ${ }^{2-4}$ However, this treatment regimen can be used in the special situation of isolated fetal hyperthyroidism. ${ }^{46}$ Isolated fetal hyperthyroidism can be developed if a pregnant woman who previously received ablative therapy for Graves' disease (radioiodine treatment or thyroidectomy) still produces high levels of TRAb. ${ }^{46}$ In such case, ATD will treat the fetal hyperthyroidism, and thyroid hormone replacement will keep the pregnant women euthyroid. The risk of such fetal hyperthyroidism can be evaluated from the measurement of maternal TRAb levels in early pregnancy. If TRAb level is elevated, a plan for biochemical and clinical monitoring should be made, including the measurement of TRAb in mid-pregnancy around week 20 and if still elevated again in the third trimester around week 30 of pregnancy.

Another important aspect to consider in late pregnancy is the risk of hyperthyroidism in the newborn child. ${ }^{5}$ Neonatal hyperthyroidism is typically present immediately after birth in children born to mothers with untreated Graves' hyperthyroidism or mothers with previous thyroid ablation who still produce TRAb. On the other hand, delayed neonatal hyperthyroidism can occur in children born to mothers who received ATD during pregnancy and up to delivery. In such case, ATD will disappear from the child immediately after birth, whereas TRAb are cleared more slowly, and so neonatal hyperthyroidism can be detected some days after birth. ${ }^{5}$ The risk of neonatal hyperthyroidism can be evaluated from the measurement of maternal TRAb levels in late pregnancy. 
Ultrasound monitoring of fetal growth, goiter, and fetal heart rate are recommended in such patients if TRAb levels are more than three times above upper reference limit.

\section{Future perspectives}

Hyperthyroidism in pregnancy is a high-risk clinical situation that both the responsible physician and the patient should be aware of. The disease should be carefully managed and controlled to prevent both maternal and fetal complications. Untreated maternal hyperthyroidism may program the fetus to the long-term development of disease, and further studies are needed to explore the hypothesis of fetal programming by maternal hyperthyroidism.

The management of hyperthyroidism before, during, and after a pregnancy involves different medical specialists (eg, general practitioner, obstetrician, endocrinologist, and pediatrician) and pertinent information to the patient. Ongoing and debatable topics on the management of hyperthyroidism in pregnancy especially refer to the diagnosis and treatment of hyperthyroidism in the first half of pregnancy. Further studies are needed on the week-to-week variation in thyroid function in early pregnancy. In addition to this, more data are needed on the risk of birth defects associated with the current available ATDs and the possibility of developing other treatments with fewer and less severe side effects.

\section{Disclosure}

The authors report no conflicts of interest in this work.

\section{References}

1. Franklyn JA, Boelaert K. Thyrotoxicosis. Lancet. 2012;379(9821): $1155-1166$.

2. Bahn RS, Burch HB, Cooper DS, et al. Hyperthyroidism and other causes of thyrotoxicosis: management guidelines of the American Thyroid Association and American Association of Clinical Endocrinologists. Thyroid. 2011;21(6):593-646.

3. De Groot L, Abalovich M, Alexander EK, et al. Management of thyroid dysfunction during pregnancy and postpartum: an Endocrine Society clinical practice guideline. J Clin Endocrinol Metab. 2012;97(8):2543-2565.

4. Stagnaro-Green A, Abalovich M, Alexander E, et al. Guidelines of the American Thyroid Association for the diagnosis and management of thyroid disease during pregnancy and postpartum. Thyroid. 2011;21(10):1081-1125.

5. Cooper DS, Laurberg P. Hyperthyroidism in pregnancy. Lancet Diabetes Endocrinol. 2013;1(3):238-249.

6. Carlé A, Pedersen IB, Knudsen N, et al. Epidemiology of subtypes of hyperthyroidism in Denmark: a population-based study. Eur $J$ Endocrinol. 2011;164(5):801-809.

7. Pedersen IB, Handberg A, Knudsen N, Heickendorff L, Laurberg P. Assays for thyroid-stimulating hormone receptor antibodies employing different ligands and ligand partners may have similar sensitivity and specificity but are not interchangeable. Thyroid. 2010;20(2):127-133.

8. Laurberg P, Cerqueira C, Ovesen L, et al. Iodine intake as a determinant of thyroid disorders in populations. Best Pract Res Clin Endocrinol Metab. 2010;24(1):13-27.
9. Laurberg P, Andersen SL. Endocrinology in pregnancy: pregnancy and the incidence, diagnosing and therapy of Graves' disease. Eur $J$ Endocrinol. In press.

10. Andersen SL, Olsen J, Carlé A, Laurberg P. Hyperthyroidism incidence fluctuates widely in and around pregnancy and is at variance with some other autoimmune diseases: a Danish population-based study. J Clin Endocrinol Metab. 2015;100(3):1164-1171.

11. Weetman AP. The immunology of pregnancy. Thyroid. 1999;9(7): 643-646.

12. Laurberg P. Remission of Graves' disease during anti-thyroid drug therapy. Time to reconsider the mechanism? Eur J Endocrinol. 2006; 155(6):783-786

13. Amino N, Tanizawa $\mathrm{O}$, Mori $\mathrm{H}$, et al. Aggravation of thyrotoxicosis in early pregnancy and after delivery in Graves' disease. J Clin Endocrinol Metab. 1982;55(1):108-112.

14. Lee RH, Spencer CA, Mestman JH, et al. Free T4 immunoassays are flawed during pregnancy. Am J Obstet Gynecol. 2009;200(3): 260.e1-260.e6.

15. Bliddal S, Feldt-Rasmussen U, Boas M, et al. Gestational age-specific reference ranges from different laboratories misclassify pregnant women's thyroid status: comparison of two longitudinal prospective cohort studies. Eur J Endocrinol. 2013;170(2):329-339.

16. Laurberg P, Andersen SL, Hindersson P, Nohr EA, Olsen J. Dynamics and predictors of serum TSH and fT4 reference limits in early pregnancy: a study within the Danish National Birth Cohort. J Clin Endocrinol Metab. 2016;101(6):2484-2492.

17. Casey BM, Dashe JS, Wells CE, McIntire DD, Leveno KJ, Cunningham FG. Subclinical hyperthyroidism and pregnancy outcomes. Obstet Gynecol. 2006;107(2 Pt 1):337-341.

18. Gudernatsch JF. Feeding experiments on tadpoles. Arch Entwicklungsmech Org. 1912;35(3):457-483.

19. Colicchia M, Campagnolo L, Baldini E, Ulisse S, Valensise H, Moretti C. Molecular basis of thyrotropin and thyroid hormone action during implantation and early development. Hum Reprod Update. 2014; 20(6):884-904.

20. Vissenberg R, Manders VD, Mastenbroek S, et al. Pathophysiological aspects of thyroid hormone disorders/thyroid peroxidase autoantibodies and reproduction. Hum Reprod Update. 2015;21(3):378-387.

21. Andersen SL, Olsen J, Wu CS, Laurberg P. Spontaneous abortion, stillbirth and hyperthyroidism: a Danish population-based study. Eur Thyroid J. 2014;3(3):164-172.

22. Bernal J, Pekonen F. Ontogenesis of the nuclear 3,5,3'-triiodothyronine receptor in the human fetal brain. Endocrinology. 1984;114(2): 677-679.

23. Morreale de Escobar G, Obregón MJ, Escobar del Rey F. Is neuropsychological development related to maternal hypothyroidism or to maternal hypothyroxinemia? J Clin Endocrinol Metab. 2000;85(11): 3975-3987.

24. Vulsma T, Gons MH, de Vijlder JJ. Maternal-fetal transfer of thyroxine in congenital hypothyroidism due to a total organification defect or thyroid agenesis. N Engl J Med. 1989;321(1):13-16.

25. Evans IM, Pickard MR, Sinha AK, Leonard AJ, Sampson DC, Ekins RP. Influence of maternal hyperthyroidism in the rat on the expression of neuronal and astrocytic cytoskeletal proteins in fetal brain. J Endocrinol. 2002;175(3):597-604.

26. Zhang L, Hernández VS, Medina-Pizarro M, Valle-Leija P, VegaGonzalez A, Morales T. Maternal hyperthyroidism in rats impairs stress coping of adult offspring. J Neurosci Res. 2008;86(6):1306-1315.

27. Andersen SL, Olsen J, Laurberg P. Foetal programming by maternal thyroid disease. Clin Endocrinol (Oxf). 2015;83(6):751-758.

28. Andersen SL, Laurberg P, Wu CS, Olsen J. Maternal thyroid dysfunction and risk of seizure in the child: a Danish nationwide cohort study. J Pregnancy. 2013;2013:Article ID 636705.

29. Andersen SL, Laurberg P, Wu CS, Olsen J. Attention deficit hyperactivity disorder and autism spectrum disorder in children born to mothers with thyroid dysfunction: a Danish nationwide cohort study. BJOG. 2014;121(11):1365-1374. 
30. Cooper DS. Antithyroid drugs. N Engl J Med. 2005;352(9):905-917.

31. Wing DA, Millar LK, Koonings PP, Montoro MN, Mestman JH. A comparison of propylthiouracil versus methimazole in the treatment of hyperthyroidism in pregnancy. Am J Obstet Gynecol. 1994;170 (1 Pt 1):90-95.

32. Mortimer RH, Cannell GR, Addison RS, Johnson LP, Roberts MS, Bernus I. Methimazole and propylthiouracil equally cross the perfused human term placental lobule. J Clin Endocrinol Metab. 1997;82(9):3099-3102.

33. Momotani N, Noh JY, Ishikawa N, Ito K. Effects of propylthiouracil and methimazole on fetal thyroid status in mothers with Graves' hyperthyroidism. J Clin Endocrinol Metab. 1997;82(11):3633-3636.

34. Andersen SL, Olsen J, Laurberg P. Antithyroid drug side effects in the population and in pregnancy. J Clin Endocrinol Metab. 2016; 101(4):1606-1614.

35. Milham SJ, Elledge W. Maternal methimazole and congenital defects in children. Teratology. 1972;5:125-126.

36. Mandel SJ, Brent GA, Larsen PR. Review of antithyroid drug use during pregnancy and report of a case of aplasia cutis. Thyroid. 1994; 4(1):129-133.

37. Foulds N, Walpole I, Elmslie F, Mansour S. Carbimazole embryopathy: an emerging phenotype. Am J Med Genet A. 2005;132A(2):130-135.

38. Bowman P, Osborne NJ, Sturley R, Vaidya B. Carbimazole embryopathy: implications for the choice of antithyroid drugs in pregnancy. QJM. 2012;105(2):189-193.

39. Andersen SL, Laurberg P. Antithyroid drugs and congenital heart defects: ventricular septal defect is part of the methimazole/carbimazole embryopathy. Eur J Endocrinol. 2014;171(5):C1-C3.

40. Yoshihara A, Noh J, Yamaguchi T, et al. Treatment of Graves' disease with antithyroid drugs in the first trimester of pregnancy and the prevalence of congenital malformation. J Clin Endocrinol Metab. 2012; 97(7):2396-2403.
41. Andersen SL, Olsen J, Wu CS, Laurberg P. Birth defects after early pregnancy use of antithyroid drugs: a Danish nationwide study. J Clin Endocrinol Metab. 2013;98(11):4373-4381.

42. Andersen SL, Olsen J, Wu CS, Laurberg P. Severity of birth defects after propylthiouracil exposure in early pregnancy. Thyroid. 2014;24(10):1533-1540.

43. Cooper DS, Rivkees SA. Putting propylthiouracil in perspective. J Clin Endocrinol Metab. 2009;94(6):1881-1882.

44. Glinoer D, Cooper DS. The propylthiouracil dilemma. Curr Opin Endocrinol Diabetes Obes. 2012;19(5):402-407.

45. Laurberg P, Andersen SL. Therapy of endocrine disease: antithyroid drug use in early pregnancy and birth defects: time windows of relative safety and high risk? Eur J Endocrinol. 2014;171(1):R13-R20.

46. Laurberg P, Bournaud C, Karmisholt J, Orgiazzi J. Management of Graves' hyperthyroidism in pregnancy: focus on both maternal and foetal thyroid function, and caution against surgical thyroidectomy in pregnancy. Eur J Endocrinol. 2009;160(1):1-8.

47. Mortimer RH, Tyack SA, Galligan JP, Perry-Keene DA, Tan YM. Graves' disease in pregnancy: TSH receptor binding inhibiting immunoglobulins and maternal and neonatal thyroid function. Clin Endocrinol (Oxf). 1990;32(2):141-152.

48. Laurberg P, Andersen S, Karmisholt J. Antithyroid drug therapy of Graves' hyperthyroidism: realistic goals and focus on evidence. Expert Rev Endocrinol Metab. 2006;1(1):91-102.

49. Bliddal S, Rasmussen AK, Sundberg K, Brocks V, Feldt-Rasmussen U. Antithyroid drug-induced fetal goitrous hypothyroidism. Nat Rev Endocrinol. 2011;7(7):396-406.

50. Amino N, Kuro R, Tanizawa O, et al. Changes of serum anti-thyroid antibodies during and after pregnancy in autoimmune thyroid diseases. Clin Exp Immunol. 1978;31(1):30-37.
International Journal of Women's Health

\section{Publish your work in this journal}

The International Journal of Women's Health is an international, peerreviewed open-access journal publishing original research, reports, editorials, reviews and commentaries on all aspects of women's healthcare including gynecology, obstetrics, and breast cancer. The manuscript management system is completely online and includes

\section{Dovepress}

a very quick and fair peer-review system, which is all easy to use. Visit http://www.dovepress.com/testimonials.php to read real quotes from published authors. 